\title{
"Evaluating Willingness to Pay as a Measure of the Impact of Dyslexia in Adults"
}

Daniel Herrera-Araujo, Bennett Shaywitz, John Holahan, Karen Marchione, Reissa Michaels, Sally Shaywitz, James K. Hammitt 


\title{
Evaluating Willingness to Pay as a Measure of the Impact of Dyslexia in Adults
}

\author{
Daniel Herrera-Araujo \\ Paris School of Economics, Hospinnomics \\ Bennett Shaywitz \\ Yale University School of Medicine \\ John Holahan \\ Yale University School of Medicine \\ Karen Marchione \\ Yale University School of Medicine \\ Reissa Michaels \\ Yale University School of Medicine \\ Sally Shaywitz \\ Yale University School of Medicine \\ James K. Hammitt \\ Harvard University, Center for Risk Analysis \\ Toulouse School of Economics, Université Toulouse Capitole
}

January 2017 


\begin{abstract}
While much is known about dyslexia in school-age children and adolescents, less is known about its effects on quality of life in adults. Using data from the Connecticut Longitudinal Study we provide the first estimates of the monetary value of improving reading, speaking, and cognitive skills to dyslexic and nondyslexic adults. Using a stated-preference survey, we find that dyslexic and nondyslexic individuals value improvements in their skills in reading speed, reading aloud, pronunciation, memory, and information retrieval at about the same rate. Because dyslexics have lower self-reported levels on these skills, their total willingness to pay to achieve a high level of skill is substantially greater than for non-dyslexics. However, dyslexic individuals' willingness to pay (averaging $\$ 3000$ for an improvement in all skills simultaneously) is small compared with the difference in earnings between dyslexic and non-dyslexic adults. We estimate that dyslexic individuals earn 15 percent less per year (about \$8000) than non-dyslexic individuals. Although improvements in reading, speaking and cognitive skills in adulthood are unlikely to eliminate the earnings difference that reflects differences in educational attainment and other factors, stated-preference estimates of the value of cognitive skills may substantially underestimate the value derived from effects on lifetime earnings and health.
\end{abstract}

Keywords: Dyslexia, contingent valuation, willingness to pay, reading JEL codes: D03, D12, L13, L22, L81 


\section{Introduction}

Developmental dyslexia, an unexpected difficulty in accuracy or fluency of reading for an individual's chronological age or intelligence, is the most common neurobehavioral disorder in children, affecting 17 to 21 percent of school-age children(Fletcher et al. 1994; Ferrer et al. 2010). At its core, dyslexia is a problem with phonological processing (getting to the elemental sounds of spoken language) that affects both spoken and written language and affects children and adults in both developed and developing countries (Kirsh et al. 1993; Elbro et al. 1995; OECD and Statistics Canada 1995). While the effects of dyslexia are evident in school, surprisingly little is known about how dyslexia affects the everyday lives of dyslexic adults who are no longer in school.

Low levels of adult literacy have strong effects on virtually every facet of adult life. The National Adult Literacy Survey (NALS), a 1992 cross-sectional study of a nationally representative sample of U.S. adults aged 16 years and older (Sum et al. 1999; Sum et al. 2004), found that men and women with higher levels of literacy were significantly more likely to be employed and to avoid unemployment, to be active labor-force participants, to be employed in professional, management-related and technical (rather than service, craft, and laborer/helper) occupations, to have supervisory responsibilities at their jobs; to earn significantly (two to three times) more weekly and annually; and to participate in educational and training activities. Conversely, men and women with lower levels of literacy were more likely to be poor or near poor, to rely on public assistance for financial support, and to experience chronic health problems. In a related study, Rudd et al. (2004) linked higher health literacy scores to wealth, health, reading engagement, and civic engagement. Nevertheless, identifying the consequences of dyslexia in adults in the workplace remains an elusive problem.

Dyslexia has profound long-term impacts on educational, income, and health outcomes, all of which are significantly worse for dyslexics than for their non-dyslexic peers. High-school drop-out rates for students classified as learning-disabled (80 to 90 percent of whom are dyslexic) are three to four times as large as for typical readers (Blackorby et al. 1996). Men and women with lower levels of literacy are more likely to be 
below or near national poverty levels (Kirsch et al. 1993; Reder and Vogel 1997; Rudd et al. 2004; Sum et al. 2004; White et al. 2006; Kutner et al. 2007; Rudd et al. 2007; Tamassia et al. 2007; Bynner and Parsons 2009; Kruidenier et al. 2010). In addition, adults with low levels of literacy have difficulty accessing or understanding health-related information, are hospitalized more often, and do not manage chronic diseases as well (Rudd et al. 2004; Rudd et al. 2007; Kutner et al. 2006). Overall, they are more likely to experience poor health and a shortened life span (Baker et al. 1997; Rudd et al. 2000; Kutner et al. 2006; Marcus 2006).

The effects of dyslexia on adult measures of success may be limited if either of two conditions is satisfied: (1) dyslexia-related problems are overcome later in life, or (2) there are no associations between dyslexia-related problems and future outcomes in life. We explore the extent of which dyslexia may affect adult wellbeing by investigating its impact on education, income, personal health, and life-satisfaction measures. In addition, we employ a stated-preference survey to estimate adults' willingness to pay (WTP) to enhance specific reading and speaking skills to assess how individuals with dyslexia value potential alleviation of their condition, compared with a control group.

To our knowledge, there are no available measures of the impact of dyslexia on wellbeing. WTP has been used previously in assessing how adults with a number of health conditions value improvement (e.g., Sloan et al. 1998; Brandt et al. 2012). The WTP methodology has not previously been used to evaluate dyslexia; we provide the first estimates of the effects of dyslexia on adult wellbeing using this measure.

We present stated-preference estimates of WTP for hypothetical treatments to improve five reading, speaking, and cognitive skills: reading speed; ability to read aloud; memory; ability to pronounce names and places correctly; and ability to rapidly retrieve facts and information. Enhancement of these skills can be valuable to dyslexic and non-dyslexic individuals alike. Participants are from the Connecticut Longitudinal Study, a long-running longitudinal survey of a population cohort focusing on dyslexia. Panel members were approximately 33 years old at the time of our survey and have been continuously enrolled in the study since about age five. 
We observe strong socioeconomic differences between respondents with and without dyslexia. Dyslexic individuals are less likely to have an undergraduate or graduate diploma. This difference in educational attainment may be an important contributor to the large income differences that we identify. Dyslexic individuals earn an estimated 15 percent less per year (around \$8000) than non-dyslexic individuals and have about 30 percent smaller net worth by age 33 than their non-dyslexic counterparts (around $\$ 60,000$ ). Additionally, dyslexic individuals have worse self-reported health than non-dyslexic individuals. Nevertheless, we do not observe any statistically significant difference in selfreported life satisfaction between dyslexic and non-dyslexic individuals, which is consistent with hedonic adaptation as found in the life-satisfaction literature (Shane et al. 1999).

We find that both dyslexic and non-dyslexic individuals have positive WTP for all five of the skills we consider. The estimated rates of WTP per unit improvement in skill are similar, except dyslexic individuals are willing to pay significantly more than non-dyslexics to improve their skill in reading aloud. Because dyslexics have on average lower skill levels than non-dyslexics, their WTP to improve each skill to a common level is larger. However, dyslexic individuals' willingness to pay is small compared with the difference in earnings between dyslexic and non-dyslexic adults. Dyslexic individuals' average WTP for an improvement in all skills is approximately $\$ 3000$, less than the estimated $\$ 8000$ difference in annual earnings. Because the observed earnings differential reflects differences in educational attainment and other factors, interventions to improve skills at age 33 will not shift dyslexic individuals to the earnings trajectories they would have followed had their skills been improved as children. Nevertheless, we suspect that stated-preference estimates of the value of cognitive skills may substantially underestimate the value derived from effects on lifetime earnings and health.

The paper is organized as follows. Section 2 describes the theoretical model. Section 3 presents the empirical implementation and data. Section 4 reports results and Section 5 presents tests of validity and robustness. Section 6 concludes. 


\section{Theoretical model}

We explore individuals' tradeoffs between wealth (which can be used for many purposes) and improvements in reading or speaking skills. Take a simple preference specification where individuals derive utility from wealth $(w)$ and current skill level (s). We define the utility function $a s u=u(w, s)$. Using stated-preference methods, one can elicit WTP for a discrete improvement in skill. Let WTP to increase skill level by the amount $e$ be denoted by the compensating variation $C(w, s, e)$.

Increasing skill by the amount $e$ while paying the amount $C$ leaves the individual with the same utility as forgoing the improvement:

$$
u(w-C(e, w, s), s+e)=u(w, s)
$$

We assume utility is increasing and concave in wealth $\left(\frac{\partial u}{\partial w}>0, \frac{\partial^{2} u}{\partial^{2} w}<0\right)$ and increasing in skill $\left(\frac{\partial u}{\partial s}>0\right)$ but make no assumptions about higher-order derivatives or cross-derivatives with respect to skill. To simplify notation, let $C=C(e, w, s), u=u(w, s)$, and $U=u(w-$ $C, s+e)$. Differentiating (1) with respect to $e$ yields:

$$
\frac{\partial C}{\partial e}=\frac{\frac{\partial U}{\partial s}}{\frac{\partial U}{\partial w}}>0
$$

i.e., WTP is increasing in the magnitude of the skill improvement, which is intuitive. Differentiating (1) with respect to s yields:

$$
\frac{\partial C}{\partial s}=\frac{\frac{\partial U}{\partial s}-\frac{\partial u}{\partial s}}{\frac{\partial U}{\partial w}}
$$

which implies that the effect of baseline skill on WTP for an improvement may be positive 
or negative. Differentiating (1) with respect to wealth yields:

$$
\frac{\partial C}{\partial w}=\frac{\frac{\partial U}{\partial w}-\frac{\partial u}{\partial w}}{\frac{\partial U}{\partial w}}=1-\frac{\frac{\partial u}{\partial w}}{\frac{\partial U}{\partial w}}
$$

which also may be positive or negative. By combining expressions (2) - (4) we obtain:

$$
\left.\frac{\partial C}{\partial e}\right|_{e=0} \equiv \frac{\partial C(0, w, s)}{\partial e}=\frac{\frac{\partial C}{\partial e}-\frac{\partial C}{\partial s}}{1-\frac{\partial C}{\partial w}}>0 .
$$

Equation (5) provides an exact method for computing the marginal rate of willingness to pay (MWTP) evaluated at zero improvement, using practical estimates of WTP for a non-zero improvement. The model that yields equation (5) accounts for any change in MWTP as skill improves or wealth declines as the individual buys more skill improvement.

Equation (5) reveals a link between WTP for skill improvement, skill level, and wealth. Although the signs of both the numerator and denominator are ambiguous, their ratio is always positive. This implies that the numerator and denominator have the same sign. It follows that if the increase in WTP in response to an increase in wealth is less (greater) than one for one, then the effect of baseline skill on the marginal rate of WTP must be smaller (larger) than the marginal rate of WTP for a skill increase. Nevertheless, without imposing more structure on the utility function, the exact relationship between WTP, wealth, and skill level is an empirical question.

\section{Methods}

\subsection{Data}

Data come from participants in the Connecticut Longitudinal Study (Shaywitz et al. 1990; Shaywitz et al. 1992; Shaywitz et al. 1999; Ferrer et al. 1999; Ferrer et al. 2007; Ferrer et al. 2015), a longitudinal panel of individuals focusing on dyslexia. At enrollment, 
individuals were representative of the children entering public kindergarten in Connecticut in 1983. For each participant, we collected information on reading from 1st to 12 th grade annually and IQ scores at $3^{r d}, 5^{\text {th }}, 7^{\text {th }}, 9^{\text {th }}$ and $11^{\text {th }}$ grades (Woodcock and Johnson 1977; Woodcock and Johnson 1989; Wechsler 1974; Wechsler 1981). A reading cluster score was computed using letter-word identification, word attack (decoding) and passage comprehension (Woodcock and Johnson 1989). Dyslexia was identified as a reading cluster score 1.5 standard errors below the score predicted from the full scale IQ or a reading cluster score below 90 (Shaywitz et al. 1992).

At age 33, a total of 442 participants were asked questions to elicit their WTP for hypothetical treatments to improve their: reading speed; ability to read aloud; memory; ability to pronounce names and places correctly; and ability to rapidly retrieve facts and information. The survey yielded $N=327$ completed interviews, a response rate of 74 percent.

Table 1 provides statistics on the respondents' demographic characteristics. Respondents are 85 percent white and 54 percent female. A third of respondents' mothers have at least a college degree. Individuals' full scale IQ (measured in third grade) averages $111 .{ }^{1}$ Average annual personal income is $\$ 48,300$ (2005 dollars). ${ }^{2}$ Self-reported health, measured on a scale from 0 (poor health) to 1 (excellent), averages 0.68 . Life satisfaction is elicited by asking respondents to rate how much they agree or disagree with the statement "I am satisfied with my life" using a scale from 1 (strongly disagree) to 10 (strongly agree) that we normalized to a scale from 0 to 1 . The normalized score averages 0.69 . Slightly over half the respondents (53 percent) have at least an

\footnotetext{
${ }^{1}$ Full scale IQ measured in third grade is highly correlated with full scale IQ measured in ninth grade, eleventh grade, and at age 33.

${ }^{2}$ Income information is elicited using an ordered categorical question. Respondents were asked about their total personal and total household income for the past 12 months and their approximate net worth (including home, net of debt). Categories ranged from "less than 5,000 dollars" to "more than 100,000 dollars" for the personal and household questions and from "less than 10,000 dollars" to "over a 1,000,000 dollars" for net worth. We summarize these responses using the midrange for each segment and the lower value for the unbounded top category.
} 
undergraduate degree by age 33 .

Following our definition, 23 percent of respondents have dyslexia. There are striking differences between respondents with and without dyslexia. Respondents with dyslexia are less likely to be white and female. Mothers of children with dyslexia are less educated than other mothers. Full scale IQ scores for respondents without dyslexia are on average higher than for respondents with dyslexia. There are large differences in personal income, per capita household income, and net worth between respondents with and without dyslexia. Respondents with dyslexia earn less and have lower net worth on average. Self-reported assessments on health and life satisfaction tend to be better for respondents without dyslexia than for respondents with dyslexia. Finally, respondents without dyslexia are more likely to have undergraduate and graduate degrees.

We elicited respondent's self-reported level for each of the five skills using a scale from 1 to 5 , where 5 corresponds to "very good" and 1 to "very bad". We then elicited WTP to improve each skill individually and all five skills jointly. The skill improvement was defined as one that would raise the individual's level on that skill to "very good." Skill improvement was to be produced by participating in a hypothetical intervention that required engaging in two, one-hour training sessions per week, lasting for two months. The cost to the respondent was to be paid as a one-time fee and would not be covered by insurance. ${ }^{3}$

We normalized the self-reported skills to a scale from 0 to 1 and calculated the possible improvement on each skill by subtracting this transformed value from 1 . We computed the "All skills" improvement as the arithmetic mean across all five skill improvements. As shown in Table 2, the hypothetical skill improvements are larger on average for dyslexics than non-dyslexics and differ substantially between skills. Using the normalized scale (0 to 1), average skill improvements for dyslexic individuals range

\footnotetext{
${ }^{3}$ Due to survey-format restrictions, valuation questions were not randomized but asked in the same order for all respondents (reading speed, reading aloud, memory, pronunciation, information retrieval, all skills). Hence any question-order effects may bias our estimates. In particular, WTP for all five improvements jointly may be biased downward relative to WTP for individual skills (Payne et al. 2000). 
between 0.37 (for pronunciation) and 0.43 (for memory). For non-dyslexics, the range is between 0.21 (for reading aloud) and 0.35 (for information retrieval). The largest difference in a self-reported skill between dyslexic and non-dyslexic individuals (0.19) is for reading aloud and the smallest difference (0.05) is for information retrieval.

WTP was elicited using a double-bounded dichotomous-choice question format (Hanemann et al. 1991; Carson and Hanemann 2005; Train 2009). Respondents were first asked if they would participate in the intervention if the cost were $X=\$ 1000$. Those who responded "yes" (they would participate) were then asked if they would participate if the cost were $2 X(=\$ 2000)$; those who responded "no" to the first offer were asked if they would participate if the cost were $X / 2(=\$ 500)$. To limit any effects of differences in the initial bid that could bias estimates of the relative valuation of different skills, a common value (\$1000) was used as the initial bid for all skills. For logistical reasons, this same value was presented to all respondents.

\subsection{Empirical strategy}

We evaluate the effects of an individual's dyslexia (denoted using the indicator variable $D Y S_{i}$ ) on a variety of measures of life outcomes, including personal income, household income (per capita), net worth, self-reported health, and life satisfaction. Let $Y$ denote an outcome variable. The effect of dyslexia on the outcome of interest can be estimated using the following OLS regression:

$$
Y_{i}=\alpha+\beta \times D Y S_{i}+\mathrm{X}_{i} \times \gamma+\mu_{i}
$$

where $\mathrm{X}_{i}$ is a vector of demographic variables and $\mu_{i}$ rationalizes all other idiosyncratic variation. The coefficient of interest is $\beta$.

We also estimate individuals' WTP for an increase in skill. Each individual is asked to answer questions about her WTP on $T(=6)$ choice occasions. Following our theoretical model, define the observed WTP, $C_{i}\left(e_{i t}, w_{i}, s_{i t}\right)$, of respondent $i$ on choice occasion $t$ for a skill improvement $e_{i t}$ as: 


$$
\log \left(C_{i t}\left(e_{i t}, w_{i}, s_{i t}\right)\right)=\beta_{1} \times e_{i t}+\beta_{2} \times s_{i \mathrm{t}}+\beta_{4} \times D Y S_{i}+\beta_{5} \times w_{i}+\mathrm{X}_{i} \times \beta_{6}+\epsilon_{i t},
$$

where $e_{i t}, s_{i t}$ and $w_{i}$ correspond to skill improvement, baseline skill and personal income, respectively; $\mathrm{X}_{i}$ contains other individual characteristics, and $\epsilon_{i t}$ rationalizes all remaining choice-to-choice individual variation.

Given the construction of our survey, skill improvement is defined as $e_{i t}=s_{\max }-s_{i t}$, where $s_{\max }$ corresponds to the maximum skill level. Hence we are not able to separately identify the effects of baseline skill and skill improvement. Our estimating equation corresponds to:

$$
\log \left(C_{i t}(e, w, s)\right)=\beta_{1} \times s_{\max }+\beta_{3} \times s_{i \mathrm{t}}+\beta_{4} \times D Y S_{i}+\beta_{5} \times w_{i}+\mathrm{X}_{i} \times \beta_{6}+\epsilon_{i t},
$$

where $\beta_{1} s_{\max }$ is estimated by the intercept and $\beta_{3}$ equals the combined effects of baseline skill and skill improvement $\left(\beta_{2}-\beta_{1}\right)$.

Double-bounded binary-choice questions determine individuals' WTP up to an interval (Hanemann et al. 1991; Carson and Hanemann 2005; Train 2009). A first bid is proposed to the agent, which she can accept ("Yes") or decline ("No"). A second question follows, in which the bid is larger if the agent accepts the initial bid and smaller otherwise. Let $b_{i t 0}$ represent the logarithm of the initial bid for individual $i$ at choice $t$, and $b_{i t U}$ and $b_{i t L}$ represent the logarithms of the larger and smaller follow-up bids, respectively. Moreover, let $x_{i}=\left\{e_{i}, w_{i}, s_{i}, X_{i}\right\}$ be a matrix of size $N \times K$ containing respondents' characteristics. We do not observe the actual $\log$ WTP, $\log \left(C_{i}(e, w, s)\right)$, but rather the interval in which it is located. If we assume $\epsilon_{i t}$ follows a normal distribution then the conditional probability of individual $i^{\prime}$ s log WTP belonging to a particular interval is given by: 


$$
Q_{i t}\left(\theta, \mathrm{x}_{i t}, y_{i t}\right)=\left\{\begin{array}{ll}
\Phi\left(\frac{b_{i t L}-x_{i} \beta}{\sigma}\right) & \text { if } y_{i t}=0 \\
\Phi\left(\frac{b_{i t 0}-x_{i} \beta}{\sigma}\right)-\Phi\left(\frac{b_{i t L}-x_{i} \beta}{\sigma}\right) & \text { if } y_{i t}=1 \\
\Phi\left(\frac{b_{i t U}-x_{i t} \beta}{\sigma}\right)-\Phi\left(\frac{b_{i t 0}-x_{i} \beta}{\sigma}\right) & \text { if } y_{i t}=2 \\
1-\Phi\left(\frac{b_{i t U}-x_{i} \beta}{\sigma}\right) & \text { if } y_{i t}=3
\end{array},\right.
$$

where $\Phi$ is the normal cumulative distribution function with mean and standard deviation $\theta=(\beta, \sigma)$. The indicator of the choice, $y_{i t}$, represents responses to the two dichotomous-choice questions of "No-No", "No-Yes", "Yes-No" and "Yes-Yes", respectively. It follows that the log-likelihood function is given by:

$$
L L(\theta)=\sum_{i=1}^{N} \sum_{t=1}^{T} \log \left(Q_{i t}\left(\theta, x_{i}, y_{i t}\right)\right)
$$

The main identifying assumption is that respondents' unobserved shocks are independent between respondents and choice occasions (Carson and Hanemann 2005). Parameters are estimated using full-information maximum likelihood.

We measure MWTP for a skill-improving intervention as dollars for a unit change in normalized skill (i.e., from "very bad"= 0 to "very good"=1). To use equation (5) to measure MWTP requires a retransformation of our estimated coefficients. We compute the median MWTP with respect to the error term for the mean respondent. Note that the numerator of equation (5) can be computed using the following expression:

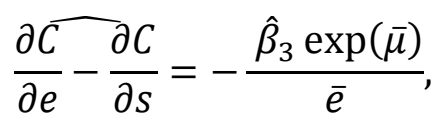

where $\beta_{3}, \bar{\mu}$ and $\bar{e}$ correspond to the skill coefficient from equation (10), the natural logarithm of WTP for the average respondent, and the average skill improvement, 
respectively. Also, note that

$$
\frac{\widehat{\partial C}}{\partial w}=\frac{\hat{\beta}_{5} \exp (\bar{\mu})}{\bar{e}}
$$

where $\beta_{5}$ corresponds to the income coefficient in equation (10). Median MWTP is computed as:

$$
\left.\frac{\partial C}{\partial e}\right|_{e=0} \equiv \frac{\partial C(0, w, s)}{\partial e}=-\frac{\hat{\beta}_{3} \exp (\bar{\mu})}{\bar{e}-\hat{\beta}_{5} \exp (\bar{\mu})}>0
$$

\section{Results}

We begin by reporting results for the regressions describing educational attainment and other life outcomes (financial, health, and life satisfaction), followed by the regressions describing WTP for skill improvements.

We describe educational attainment using an ordered-probit model. The dependent variable is an ordered-categorical variable with outcomes: no diploma, undergraduate diploma, and graduate diploma. Table 3 reports the estimated marginal effects of the independent variables on the outcome. The estimates suggest that dyslexia has a negative effect on educational attainment. Point estimates of the coefficients on dyslexia are negative for both undergraduate and graduate education, and positive for no diploma, and are significantly different from zero. In addition, whites and women are more likely to have completed higher education, and individuals whose mother received an undergraduate degree are also more likely to have an undergraduate or graduate degree.

Regression models for the other life-outcome variables are reported in Table 4. Independent variables are the same as in Table 3, but these models are estimated using ordinary least squares. The first three columns report results using as dependent variables the logarithm of personal income, the logarithm of per capita household income, and the 
logarithm of personal net worth. For these models, the estimated coefficients on dyslexia are negative but they are statistically significant only for personal and household income and not for net worth. ${ }^{4}$ Individuals with dyslexia are estimated to have a personal income 15 percent smaller than individuals without dyslexia, and household per capita income and net worth are about 30 percent smaller. We find evidence of both racial and gender differences: the estimated coefficient of white is positive and that of female is negative in all three regressions and significant in the models for personal and household income. Compared with men, women have per capita household income 15 percent smaller and personal income and net worth 30 percent smaller (the coefficient for net worth is not significant). Point estimates of the mother's education coefficients are positive across income measures but statistically significant only for household income.

The last two columns of Table 4 present estimates from ordinary least square regressions for self-reported health (column 4) and life satisfaction (column 5). Individuals with dyslexia report worse health than individuals without dyslexia, a statistically significant difference. The point estimate of the effect of dyslexia on life satisfaction is also negative, though not significantly so. White individuals report being healthier and feeling more satisfied with their life than non-white individuals. We find no statistically significant difference by gender, while mothers' education has a positive and significant impact on both measures.

In Table 5 we report the impact of dyslexia on the level of potential improvement in each skill, defined as the difference between "very good" and the respondent's selfreported skill level (on a 0 to 1 scale). Dyslexia has a consistently positive and statistically significant effect on all potential-skill-improvement variables. Mothers' education is negatively associated with potential improvement (i.e., positively associated with skill

\footnotetext{
${ }^{4}$ We also estimated the regressions reported in Table 4 controlling for IQ. The point estimates have the same sign and magnitude but are less precisely estimated. Although dyslexia is independent of true IQ, it may not be independent of measured IQ. Dyslexia is considered to be a neurobehavioral condition that is defined from birth. If dyslexia influences measured IQ, then measured IQ is a biased measure of cognitive ability.
} 
level) for reading speed and pronunciation. Women report smaller potential improvement in memory and larger potential improvement in information retrieval. Race and income are not significantly associated with potential improvement in any of the skills.

The hypothetical interventions require participation in two hour-long training sessions per week for two months. This time cost may reduce WTP compared with a situation in which there is no time cost. It could also bias estimates of the effect of income on WTP, if the cost of spending time in the training sessions is correlated with income. To account for this factor, we added an estimate of each respondent's time cost to the bid amounts. The estimated time cost is equal to the respondent's wage rate (personal income divided by an assumed 2000 working hours per year) multiplied by the 16 hours spent in the training sessions.

Table 6 reports estimates of the WTP equation described in equation (10), calculated separately for each of the six interventions and correcting for the time costs of participating in the training sessions. ${ }^{5}$ The dependent variable in each regression is the natural logarithm of WTP in 2005 dollars. Estimates are obtained using full-information maximum likelihood. For all skills (i.e., columns), WTP is negatively and significantly associated with baseline skill level; i.e., individuals with lower baseline skills value improvement more than other individuals. Controlling for baseline skill, individuals with dyslexia value improvements in reading aloud more than individuals without dyslexia, but there is no significant difference for other skills. Women have significantly smaller WTP than men for improvements in reading speed, reading aloud, memory, and all skills jointly. The estimated coefficients on income are positive and, except for pronunciation, significantly different from zero. Normally, a positive relationship between WTP for a good and income is expected. Finally, we find no significant effects of mothers' education on WTP on any skill improvement.

Our WTP questions elicit the value of improving skills up to a subjective level

\footnotetext{
${ }^{5}$ Estimates that omit the adjustment for time costs are reported in Table A1 in the appendix. The main difference is that the estimated coefficients on income are smaller than in Table 6.
} 
categorized as "very good". Our setting did not allow for exogenous changes in the baseline skill levels. Hence we cannot disentangle the effects of baseline skill and the magnitude of improvement. This limitation can be overcome by estimating marginal WTP at zero improvement using equation (5). The numerator in equation (5) coincides with our identified effect and includes the joint effects of baseline skill level and improvement on WTP. MWTP calculated from equation (12) estimates the individual's MWTP at zero skill improvement. These values are measured as dollars for a unit change in normalized skill (i.e., from "very bad" = 0 to "very good" = 1) and are reported in Table 7. Average MWTP6 for an improvement in skill ranges from $\$ 600$ dollars for the reading aloud intervention to $\$ 2400$ for the information retrieval. The values are in general larger for dyslexic than for non-dyslexic respondents, significantly so only for reading aloud. ${ }^{7}$

WTP to improve skill to a "very good" level can be estimated as the product of the potential skill improvement (Table 2) and the MWTP for that skill (Table 7). These values are shown in Table $8 .^{8}$ Although the estimated MWTP for skill improvement is generally similar for dyslexic and non-dyslexic individuals, the potential skill improvement is larger for dyslexics and hence WTP for the incremental improvement that was elicited in our survey is also larger. Total WTP to improve all five skills jointly is approximately twice as large for dyslexic as for non-dyslexic respondents (a difference of \$1500); the largest proportional difference (a factor of five) is for reading aloud. In contrast, total WTP to improve memory and information retrieval is similar, as the differences in reported levels of these skills are modest.

\footnotetext{
${ }^{6}$ We retransform predicted log WTP from the regression equation to predicted WTP (in dollars) by exponentiation, which implies our estimates of WTP are medians with respect to the error term; estimates are for the sample-mean respondent except setting $\mathrm{DYS}=0,1$, or its mean value as appropriate.

${ }^{7}$ Estimates of MWTP that do not account for the time cost of the intervention, reported in Table A2, average approximately 20 percent smaller.

${ }^{8}$ Note that these estimates of WTP for a discrete skill improvement are biased upward because they assume average WTP for the improvement equals our estimate of the marginal WTP at zero improvement. One expects that MWTP will decrease as the individual pays for successive skill increments.
} 


\section{Validity and robustness tests}

When one desirable good is nested within (is a proper subset of) another, the larger good should be valued at least as much as the smaller good (Hanemann 2004). Our results are consistent with this hypothesis as MWTP for an intervention improving all five skills jointly is larger than MWTP to improve any single skill (Figure 1). Non-dyslexic respondents' MWTP averages between $\$ 500$ and $\$ 2500$ for improvement of a single skill and about $\$ 5700$ for improvement of all five skills jointly. Dyslexic respondents' MWTP is larger: between $\$ 1300$ and $\$ 2400$ for improvement of a single skill and about $\$ 7600$ for an improvement of all five skills jointly.

We elicited WTP for skill improvements using a double-bounded binary-choice format. The initial bid is exogenous but the follow-up bid is not (Cameron and Quiggin 1994). The probability of receiving a follow-up bid larger than the initial bid corresponds to the probability that the respondent answers "yes" to the first bid. The endogeneity of the second bid could bias our estimates. As a robustness check, we compare the coefficients estimated using only the first bids to the standardized coefficients from our double-bounded binary-choice setting.

In Table 9 we report the single-bounded and the double-bounded estimates for the WTP equation described in equation (10), estimated separately for each of the five interventions. Because the initial bid was common across respondents, single-bounded estimation corresponds to a probit model. Without variation among our initial bids we cannot identify the scale of the WTP distribution from the coefficients using a standard probit (we follow the usual identification assumption of normalizing the variance of the residual error to one). To compare coefficient estimates between the double-bounded and single-bounded estimates, we divide the estimated coefficients of the double-bounded estimates by the standard deviation (scale) of the WTP distribution estimated from that equation. All specifications include the same independent variables as in Table 6, though we report only the coefficients for baseline skill. The estimated coefficients from the single- and the double-bounded frameworks are quite similar, suggesting that 
endogeneity of the second bids does not substantially bias our estimates.

\section{Discussion and conclusions}

We find that both dyslexic and non-dyslexic individuals value improvements in a variety of reading, speaking, and cognitive skills. Marginal WTP for individual skills ranges from $\$ 500$ to $\$ 2500$ for non-dyslexic individuals and somewhat more, from $\$ 1300$ to $\$ 2400$ for dyslexic individuals (these values include the imputed costs of participating in 16 hours of training sessions). The between-group difference in MWTP is not statistically significant except for reading aloud. Because dyslexics have lower selfreported skills than non-dyslexics, their total WTP for an improvement to a "very good" level is larger. In both groups, MWTP for a program to enhance all five skills simultaneously is significantly larger than MWTP for each single skill, which provides some evidence that these results can be interpreted as valid estimates of preferences. As is true with any stated-preference study, we cannot exclude the possibility that our estimates of WTP are biased downward if some respondents do not believe the interventions described would yield the stated improvements. This possibility could also affect the estimated difference in MWTP between dyslexic and non-dyslexic individuals.

Our estimates of dyslexic individuals' WTP for improvements in these skills are smaller than the difference in earnings between dyslexic and non-dyslexic adults. For example, dyslexic respondents' average WTP to improve all skills jointly to "very good" is estimated to be \$3000; in contrast, we estimate that dyslexic individuals may earn 15 percent less per year (about \$8000) than non-dyslexic individuals. ${ }^{9}$ How should this difference be interpreted?

WTP for an intervention at age 33 to improve reading, speaking, or cognitive skills should logically include the effects on future earnings and on other contributors to

\footnotetext{
${ }^{9}$ For a similar good, von Stackelberg and Hammitt (2009) used stated-preference methods to estimate parents' WTP to prevent a delay in reading attainment or an IQ deficit in their children associated with exposure to particular chemicals (PCBs) in the environment. Their findings suggest that WTP is small compared with estimates of the effect of lower IQ on lifetime earnings.
} 
wellbeing. The earnings difference observed at age 33 results from differences in educational attainment, early work experience, and other factors between dyslexic and non-dyslexic individuals; an improvement in skills at middle age is unlikely to shift dyslexic individuals to the earnings trajectory they would have followed if their skills had been improved as children. In addition, WTP should include only the individual's (posttax) share of the earnings increase. Hence, it would be unsurprising if the contribution of the interventions to future earnings were substantially smaller than the observed earnings differential. However, WTP should also include the value of skill improvement to other aspects of wellbeing, such as reading for pleasure or avoiding aggravation or embarrassment when unable to remember a name or pronounce it correctly. This component would be additional to the effect on future earnings. It is difficult to assess its potential magnitude. The absence of a significant difference in life satisfaction between dyslexic and non-dyslexic individuals suggests it may be modest, though life satisfaction may not be a sufficiently sensitive measure to detect the difference. In summary, we suspect that stated-preference estimates of reading, speaking, and cognitive skills may substantially underestimate the value of these skills.

\section{Acknowledgements}

We thank Glenn Blomquist and the two anonymous reviewers for extremely helpful comments. We also thank supporters of the Connecticut Longitudinal Study: Connecticut State Department of Education; U.S. Department of Education; U.S. National Institutes of Health; and Seedlings Foundation. 


\section{References}

Brandt, Sylvia, Vásquez L. Felipe, and Michael W. Hanemann. 2012. " Contingent Valuation Scenarios f or Chronic Illnesses: The Case of Childhood Asthma," Value in Health, 15(8): 1077-1083.

Cameron, Trudy. A., and John Quiggin. 1994. “Estimation Using Contingent Valuation Data from a 'Dichotomous Choice with Follow-Up' Questionnaire," Journal of Environmental Economics and Management, 27(3): 218-234.

Carson, Richard T., and Michael W. Hanemann. 2005. "Contingent Valuation," Handbook of Environmental Economics, Karl-Göran Mäler and Jeffrey R. Vincent (eds.), Amsterdam: Elsevier, pp. 821-936.

Elbro, Castren, Susan Moller, and Elizabeth M. Nielsen. 1995. "Functional Reading Difficulties in Denmark. A Study of Adult Reading of Common Texts," Reading and Writing: An Interdisciplinary Journal, 7(3): 257-276.

Ferrer, Emilio, Bennett Shaywitz, John Holahan, Karen Marchone, Reissa Michaels, and Sally Shaywitz. 2015. "Achievement Gap in Reading is Present as Early as First Grade and Persists through Adolescence," Journal of Pediatrics, 167(5): 1121-1125.

Ferrer, Emilio, Bennett Shaywitz, John Holahan, Karen Marchone, and Sally Shaywitz. 2010. "Uncoupling of Reading and IQ over Time: Empirical E vidence for a Definition of Dyslexia," Psychological Science, 21(1): 93-101.

Ferrer, Emilio, John J. McArdle, Bennett Shaywitz, John Holahan, Karen Marchione, and Sally Shaywitz. 2007. "Longitudinal Models of Developmental Dynamics between Reading and Cognition from Childhood to Adolescence," Developmental Psychology, 43(6): 1460-1473.

Fletcher, Jack M., Sally Shaywitz, Donald Shankweiler, Leonard Katz, Isabelle Y. Liberman, Karla Stuebing, and Bennett Shaywitz. 1994. “Cognitive Profiles of Reading Disability: Comparisons of Discrepancy and Low Achievement Definitions," Journal of Educational Psychology, 86(1): 6-23.

Hanemann, Michael W. 1994. "Valuing the Environment through Contingent Valuation," Journal of Economic Perspectives, 8(4): 19-43.

Hanemann, Michael W., John Loomis, and Barbara Kanninen. 1991. "Statistical Efficiency of Double-Bounded Dichotomous Choice Contingent Valuation," American Journal of Agricultural Economics, 73(4): 1255-1261.

Kirsch, Irwin S., Ann Jungeblut, Lynn Jenkins, and Andrew Kolstad. 1993. Adult Literacy 
in America: A First Look at the Results of the National Adult Literacy Survey. Princeton, New Jersey: Educational Testing Service.

OECD and Statistics Canada. 1995. Literacy, Economy, and Society: Results of the First International Adult Literacy Survey. Paris and Ottawa: OECD Publication Service.

Rudd, Rima, Irwin S. Kirsch, and Kentaro Yamamoto. 2004. Literacy and Health in America: Policy Information Report, Global Affairs Division. Princeton, New Jersey: Educational Testing Service.

Payne, John W., David A. Schkade, William H. Desvousges, and Chris Aultman. 2000. "Valuation of Multiple Environmental Programs," Journal of Risk and Uncertainty 21(1): 95-115.

Shane, Frederick, and George Loewenstein. 1999. "Hedonic Adaption," Well-Being: The Foundations of Hedonic Psychology, Daniel Kahneman, Ed Diener and Norbert Schwarz (eds.), New York: Sage Foundation.

Shaywitz, Sally, Jack M. Fletcher, John Holahan, Abigail Shneider, Karen Marchione, Karla Stuebing, David Francis, Kenneth R. Pugg, and Bennett Shaywitz. 1999. "Persistence of Dyslexia: The Connecticut Longitudinal Study at Adolescence," Pediatrics, 104(6): 1351-1359.

Shaywitz, Sally, Michael Escobar, Bennett Shaywitz, Jack M. Fletcher, and Robert Makuch. 1992. “Evidence that Dyslexia May Represent the Lower Tail of a Normal Distribution of Reading Ability," New England Journal of Medicine, 326(3): 145-150.

Shaywitz, Sally, Bennett Shaywitz, Jack M. Fletcher, and Michael Escobar. 1990. "Prevalence of Reading Disability in Boys and Girls: Results of the Connecticut Longitudinal Study," JAMA, 264(8): 998-1002.

Sloan, Frank A., W. Kip Viscusi, Harrel W. Chesson, Christopher J. Conover, and Kathryn Whetten-Goldstein. 1998. "Alternative Approaches to Valuing Intangible Health Losses: The Evidence for Multiple Sclerosis," Journal of Health Economics, 17(4): 475-497.

Sum, Andrew, Irwin S. Kirsch, and Kentaro Yamamoto. 2004. A Human Capital Concern: The Literacy Proficiency of U.S. Immigrants. Princeton, New Jersey: Educational Testing Service.

Sum, Andrew. 1999. Literacy in the Labor Force. Washington, DC: National Center for Education Statistics.

Train, Kenneth E. 2009. Discrete Choice Methods with Simulation. Cambridge: Cambridge University Press. 
Von Stackelberg, Katherine, and James K. Hammitt. 2009. “Use of Contingent Valuation to Elicit Willingness-to-Pay for the Benefits of Developmental Health Risk Reductions," Environmental Resource Economics, 43(1): 45-61.

Wechsler, David. 1981. Wais-R Manual: Wechsler Adult Intelligence Scale-Revised. New York: Psychological Corporation.

Wechsler, David. 1974. Wisc-R: Weschler Intelligence Scale for Children, Revised. New York: Psychological Corporation.

Woodcock, Richard W., and Mary E. Johnson. 1989. Woodcock-Johnson Tests of Cognitive Ability. Allen, Texas: DLM Teaching Resources.

Woodcock, Richard W., and Mary E. Johnson. 1977. The Psycho-Educational Battery. Allen TX: DLM Teaching Resources. 
Table 1. Summary statistics

(Sample means and standard deviations)

\begin{tabular}{|c|c|c|c|c|c|c|}
\hline & \multicolumn{2}{|c|}{ All } & \multicolumn{2}{|c|}{ Non-DYS } & \multicolumn{2}{|c|}{ DYS } \\
\hline & & $\mathrm{N}$ & & $\mathrm{N}$ & & $\mathrm{N}$ \\
\hline Dyslexic & $\begin{array}{c}0.23 \\
(0.42)\end{array}$ & 327 & & & & \\
\hline White & $\begin{array}{c}0.85 \\
(0.35)\end{array}$ & 327 & $\begin{array}{c}0.91 \\
(0.29)\end{array}$ & 251 & $\begin{array}{c}0.69 \\
(0.46)\end{array}$ & 76 \\
\hline Female & $\begin{array}{c}0.54 \\
(0.50)\end{array}$ & 327 & $\begin{array}{c}0.57 \\
(0.50)\end{array}$ & 251 & $\begin{array}{c}0.47 \\
(0.50)\end{array}$ & 76 \\
\hline Mothers' degree & $\begin{array}{c}0.33 \\
(0.47)\end{array}$ & 323 & $\begin{array}{c}0.38 \\
(0.49)\end{array}$ & 247 & $\begin{array}{c}0.16 \\
(0.37)\end{array}$ & 76 \\
\hline Full scale IQ grade 3 & $\begin{array}{l}111.49 \\
(14.88)\end{array}$ & 327 & $\begin{array}{l}114.17 \\
(12.97)\end{array}$ & 251 & $\begin{array}{l}102.65 \\
(17.13)\end{array}$ & 76 \\
\hline Personal income & $\begin{array}{c}4.83 \\
(3.14)\end{array}$ & 325 & $\begin{array}{c}5.07 \\
(3.17)\end{array}$ & 249 & $\begin{array}{c}4.05 \\
(2.83)\end{array}$ & 76 \\
\hline Household income & $\begin{array}{c}7.60 \\
(3.32)\end{array}$ & 325 & $\begin{array}{c}8.03 \\
(3.22)\end{array}$ & 249 & $\begin{array}{c}6.20 \\
(3.85)\end{array}$ & 76 \\
\hline Personal net worth & $\begin{array}{c}13.31 \\
(25.50)\end{array}$ & 312 & $\begin{array}{c}14.87 \\
(27.35)\end{array}$ & 238 & $\begin{array}{c}8.27 \\
(18.15)\end{array}$ & 74 \\
\hline Personal health & $\begin{array}{c}0.68 \\
(0.24)\end{array}$ & 327 & $\begin{array}{c}0.70 \\
(0.21)\end{array}$ & 251 & $\begin{array}{c}0.60 \\
(0.28)\end{array}$ & 76 \\
\hline Life satisfaction & $\begin{array}{c}0.69 \\
(0.23)\end{array}$ & 327 & $\begin{array}{c}0.70 \\
(0.30)\end{array}$ & 251 & $\begin{array}{c}0.65 \\
(0.28)\end{array}$ & 76 \\
\hline Undergraduate & $\begin{array}{c}0.33 \\
(0.47)\end{array}$ & 327 & $\begin{array}{c}0.36 \\
(0.48)\end{array}$ & 251 & $\begin{array}{c}0.25 \\
(0.44)\end{array}$ & 76 \\
\hline Graduate & $\begin{array}{c}0.20 \\
(0.40)\end{array}$ & 327 & $\begin{array}{c}0.24 \\
(0.43) \\
\end{array}$ & 251 & $\begin{array}{c}0.04 \\
(0.20) \\
\end{array}$ & 76 \\
\hline
\end{tabular}

Notes: DYS (dyslexic), White, Female, Undergraduate, Graduate, Mothers' degree are indicator variables coded 1 if true and 0 otherwise. Full scale IQ is measured when the individual was in 3th grade. Personal, household income and net worth are in units of ten thousand dollars (2005). We summarize these responses using the midrange for each segment and the lower value for the unbounded top category. Life Satisfaction is from individuals' agreement with the statement "I am satisfied with my life" (normalized to range from $0=$ "strongly disagree" to 1 = "strongly agree"). Personal health values range from $0=$ "poor" to $1=$ "Excellent" health. 
Table 2. Self-reported skill (SRS) improvement

\begin{tabular}{lcc}
\hline & Non-DYS & DYS \\
\hline Reading speed & 0.26 & 0.40 \\
& $(0.25)$ & $(0.26)$ \\
Reading aloud & 0.21 & 0.40 \\
& $(0.25)$ & $(0.28)$ \\
Memory & 0.34 & 0.43 \\
& $(0.30)$ & $(0.32)$ \\
Pronunciation & 0.23 & 0.37 \\
& $(0.22)$ & $(0.28)$ \\
Information retrieval & 0.35 & 0.40 \\
& $(0.24)$ & $(0.25)$ \\
All skills & 0.27 & 0.40 \\
& $(0.17)$ & $(0.20)$ \\
\hline
\end{tabular}

Notes: Improvements for each skill are measured as the difference between self-reported skill level (SRS) and the highest SRS possible value (5) and normalizing to the zero-one scale. "All skills" improvement is the mean of the five individual improvements. 
No diploma

Dyslexic

White

Female

Mothers' degree
(1)

$0.198^{* * *}$

(0.050)

(2) Undergraduate

$-0.225^{* * *}$

(0.0790)

$-0.127^{* * *}$

(0.0421)

$-0.301^{* * *}$

(0.03)
$-0.0571^{* * *}$

(0.0150)

$0.0649^{* * *}$

$(0.0243)$

$0.0366^{* * *}$

(0.0133)

$0.0870^{* * *}$

(0.0194)
Graduate

$-0.141^{* * *}$

(0.0393)

$0.160^{* * *}$

(0.0580)

$0.0904^{* * *}$

(0.0307)

$0.215^{* * *}$

(0.0285)

Notes: The number of observations is 322. The estimation is done using an ordered probit. Dependent variable is education. Regression follows from equation (8). Robust standard errors are in parentheses: ${ }^{*}$ significant at $10 \%$; ${ }^{* *}$ significant at $5 \%$; ${ }^{* *}$ significant at $1 \%$. Dyslexic, White, Female and Mothers' degree are defined in Table 1. 
Table 4. Dyslexia's impact on income, health and life satisfaction

(1)

(3)

(4)

(5)

Log Log

\begin{tabular}{lccccc} 
& $\begin{array}{c}\text { personal } \\
\text { income }\end{array}$ & $\begin{array}{c}\text { household } \\
\text { income }\end{array}$ & $\begin{array}{c}\text { Log net } \\
\text { worth }\end{array}$ & $\begin{array}{c}\text { Personal } \\
\text { Health }\end{array}$ & $\begin{array}{c}\text { Life } \\
\text { satisfaction }\end{array}$ \\
\hline Dyslexic & $-0.153^{*}$ & $-0.282^{* *}$ & -0.316 & $-0.0872^{* *}$ & -0.0164 \\
White & $(0.0891)$ & $(0.110)$ & $(0.231)$ & $(0.0360)$ & $(0.0367)$ \\
& $0.210^{*}$ & $0.362^{* * *}$ & 0.267 & $0.0840^{*}$ & $0.126^{* * *}$ \\
Female & $(0.120)$ & $(0.127)$ & $(0.277)$ & $(0.0434)$ & $(0.0421)$ \\
& $-0.313^{* * *}$ & $-0.151^{* *}$ & -0.287 & 0.0171 & 0.00490 \\
& $(0.0690)$ & $(0.0720)$ & $(0.197)$ & $(0.0260)$ & $(0.0261)$
\end{tabular}

Mothers'

degree

0.110

$0.160^{* *}$

0.0809

$0.0533^{* *}$

$0.0520^{* *}$

Constant

(0.0786)

$(0.0807)$

(0.227)

$(0.0270)$

$(0.0253)$

$1.582^{* * *}$

$0.902^{* * *}$

$1.167^{* * *}$

$0.606^{* * *}$

$0.573^{* * *}$

(0.128)

(0.129)

(0.299)

(0.0436)

(0.0448)

$\begin{array}{llllll}\text { Observations } & 320 & 316 & 307 & 322 & 322\end{array}$

R-squared

0.096

0.112

0.019

0.072

0.057

Notes: All regressions are ordinary least squares. The number of observations varies because of missing values. Regressions follow from equation (8). Robust standard errors are in parentheses: ${ }^{*}$ significant at $10 \%$; ${ }^{* *}$ significant at $5 \%$; ${ }^{* *}$ significant at $1 \%$. 
Table 5. Dyslexia's impact on self-reported potential improvements

\begin{tabular}{|c|c|c|c|c|c|c|}
\hline & $\begin{array}{c}(1) \\
\text { Reading } \\
\text { Speed }\end{array}$ & $\begin{array}{c}(2) \\
\text { Reading } \\
\text { Aloud } \\
\end{array}$ & Memory & $\begin{array}{c}(4) \\
\text { Pronun- } \\
\text { ciation } \\
\end{array}$ & $\begin{array}{c}(5) \\
\text { Info. } \\
\text { Retrieval }\end{array}$ & $\begin{array}{c}\text { (6) } \\
\text { All skills } \\
\end{array}$ \\
\hline Dyslexic & $\begin{array}{l}0.142^{* * *} \\
-0.0346\end{array}$ & $\begin{array}{l}0.211^{* * *} \\
(0.0363)\end{array}$ & $\begin{array}{l}0.104^{* *} \\
(0.0421)\end{array}$ & $\begin{array}{l}0.144^{* * *} \\
(0.0368)\end{array}$ & $\begin{array}{l}0.0553^{*} \\
(0.0330)\end{array}$ & $\begin{array}{l}0.131^{* * *} \\
(0.0261)\end{array}$ \\
\hline White & $\begin{array}{c}0.0424 \\
(0.0383)\end{array}$ & $\begin{array}{c}0.0611 \\
(0.0402)\end{array}$ & $\begin{array}{c}0.0211 \\
(0.0496)\end{array}$ & $\begin{array}{c}0.0237 \\
(0.0407)\end{array}$ & $\begin{array}{l}-0.0525 \\
(0.0385)\end{array}$ & $\begin{array}{c}0.0192 \\
(0.0286)\end{array}$ \\
\hline Female & $\begin{array}{l}-0.0237 \\
(0.0299)\end{array}$ & $\begin{array}{l}0.00362 \\
(0.0307)\end{array}$ & $\begin{array}{l}-0.0649^{*} \\
(0.0352)\end{array}$ & $\begin{array}{c}0.0173 \\
(0.0280)\end{array}$ & $\begin{array}{l}0.0588^{* *} \\
(0.0273)\end{array}$ & $\begin{array}{c}0.0018 \\
(0.0211)\end{array}$ \\
\hline $\begin{array}{l}\text { Personal } \\
\text { income }\end{array}$ & $\begin{array}{c}0.00609 \\
(0.00474)\end{array}$ & $\begin{array}{c}0.00249 \\
(0.00522)\end{array}$ & $\begin{array}{c}0.00553 \\
(0.00559)\end{array}$ & $\begin{array}{c}0.00302 \\
(0.00412)\end{array}$ & $\begin{array}{l}-0.00133 \\
(0.00475)\end{array}$ & $\begin{array}{c}0.00316 \\
(0.00336)\end{array}$ \\
\hline $\begin{array}{l}\text { Mother's } \\
\text { education }\end{array}$ & $\begin{array}{l}-0.0568^{*} \\
(0.0319)\end{array}$ & $\begin{array}{l}-0.0425 \\
(0.0292)\end{array}$ & $\begin{array}{c}0.0278 \\
(0.0349)\end{array}$ & $\begin{array}{c}-0.0632^{* *} \\
(0.0275)\end{array}$ & $\begin{array}{c}-0.00214 \\
(0.0287)\end{array}$ & $\begin{array}{l}-0.0275 \\
(0.0205)\end{array}$ \\
\hline Constant & $\begin{array}{l}0.221^{* * *} \\
(0.0463)\end{array}$ & $\begin{array}{l}0.151^{* * *} \\
(0.0505)\end{array}$ & $\begin{array}{l}0.324^{* * *} \\
(0.0577)\end{array}$ & $\begin{array}{l}0.209^{* * *} \\
(0.0472)\end{array}$ & $\begin{array}{l}0.370^{* * *} \\
(0.0445)\end{array}$ & $\begin{array}{l}0.255^{* * *} \\
(0.0335)\end{array}$ \\
\hline $\begin{array}{l}\text { Observations } \\
\text { R-squared }\end{array}$ & $\begin{array}{c}320 \\
0.071\end{array}$ & $\begin{array}{c}320 \\
0.114\end{array}$ & $\begin{array}{c}320 \\
0.040\end{array}$ & $\begin{array}{c}320 \\
0.079\end{array}$ & $\begin{array}{c}320 \\
0.035\end{array}$ & $\begin{array}{c}320 \\
0.035\end{array}$ \\
\hline
\end{tabular}

Notes: All regressions are ordinary least squares. Improvement is defined in Table 2. The number of observations varies because of missing values. Regressions follow from equation (8). Robust standard errors are in parentheses: ${ }^{*}$ significant at $10 \%$; ${ }^{* *}$ significant at $5 \%$; *** significant at $1 \%$. 
Table 6. Willingness to pay regression results

\begin{tabular}{lcccccc}
\hline & $(1)$ & $(2)$ & $(3)$ & $(4)$ & $(5)$ & $(6)$ \\
& $\begin{array}{c}\text { Reading } \\
\text { Speed }\end{array}$ & $\begin{array}{c}\text { Reading } \\
\text { Aloud }\end{array}$ & Memory & $\begin{array}{c}\text { Pronun- } \\
\text { ciation }\end{array}$ & $\begin{array}{c}\text { Information } \\
\text { retrieval }\end{array}$ & All skills \\
\hline Dyslexic & 0.212 & $1.031^{*}$ & -0.00184 & 0.442 & -0.0287 & 0.258 \\
& $(0.345)$ & $(0.562)$ & $(0.229)$ & $(0.425)$ & $(0.236)$ & $(0.245)$ \\
Baseline skill & $-2.484^{* * *}$ & $-3.686^{* * *}$ & $-1.091^{* * *}$ & $-3.229^{* * *}$ & $-2.079^{* * *}$ & $-2.299^{* * *}$ \\
& $(0.607)$ & $(1.023)$ & $(0.300)$ & $(0.804)$ & $(0.443)$ & $(0.512)$ \\
White & -0.255 & -0.262 & -0.171 & -0.288 & -0.279 & -0.266 \\
Female & $(0.469)$ & $(0.692)$ & $(0.273)$ & $(0.511)$ & $(0.296)$ & $(0.266)$ \\
& $-1.196^{* * *}$ & $-1.154^{* *}$ & $-0.463^{* *}$ & -0.181 & -0.236 & $-0.396^{* *}$ \\
Income & $(0.328)$ & $(0.530)$ & $(0.186)$ & $(0.357)$ & $(0.196)$ & $(0.187)$ \\
& $0.109^{* *}$ & $0.144^{* *}$ & $0.0772^{* *}$ & 0.0391 & $0.111^{* * *}$ & $0.162^{* * *}$ \\
Mothers' & $(0.0502)$ & $(0.0721)$ & $(0.0320)$ & $(0.0594)$ & $(0.0322)$ & $(0.0311)$ \\
education & & & & & & \\
& 0.252 & 0.304 & 0.213 & 0.338 & 0.151 & 0.227 \\
Constant & $(0.311)$ & $(0.547)$ & $(0.195)$ & $(0.361)$ & $(0.200)$ & $(0.194)$ \\
& $7.074^{* * *}$ & $6.127^{* * *}$ & $6.693^{* * *}$ & $6.710^{* * *}$ & $7.147^{* * *}$ & $7.764^{* * *}$ \\
& $(0.722)$ & $(1.139)$ & $(0.384)$ & $(0.853)$ & $(0.430)$ & $(0.506)$ \\
Sigma & $1.865^{* * *}$ & $2.563^{* * *}$ & $1.293^{* * *}$ & $1.878^{* * *}$ & $1.343^{* * *}$ & $1.365^{* * *}$ \\
& $(0.222)$ & $(0.464)$ & $(0.123)$ & $(0.287)$ & $(0.136)$ & $(0.121)$ \\
\hline
\end{tabular}

Notes: All regressions are maximum likelihood estimates. Dependent variable is log WTP for indicated skill. Regressions follow from equation (10). Improvements are computed as explained in Table 2. Robust standard errors are in parentheses: ${ }^{*}$ significant at $10 \%$; ${ }^{*}$ significant at $5 \% ;{ }^{* *}$ significant at $1 \%$. 
Table 7. Marginal willingness to pay for improvement intervention

\begin{tabular}{lccc}
\hline & Mean & Non-DYS & DYS \\
& DYS $=0.23$ & DYS $=0$ & DYS $=1$ \\
\hline Reading speed & $1469^{* * *}$ & $1403^{* * *}$ & $1792^{* * *}$ \\
Reading aloud & $(364)$ & $(345)$ & $(436)$ \\
& $622^{* * *}$ & $506^{* * *}$ & $1373^{* * *}$ \\
Memory & $(173)$ & $(140)$ & $(382)$ \\
& $1282^{* *}$ & $1281^{* * *}$ & $1298^{* * *}$ \\
Pronunciation & $(356)$ & $(350)$ & $(357)$ \\
& $1072^{* * *}$ & $981^{* * *}$ & $1551^{* * *}$ \\
Information retrieval & $(265)$ & $(242)$ & $(386)$ \\
& $2446^{* * *}$ & $2463^{* * *}$ & $2426^{* * *}$ \\
All skills & $(521)$ & $(528)$ & $(515)$ \\
& $6016^{* * *}$ & $5662^{* * *}$ & $7577^{* * *}$ \\
& $(1338)$ & $(1260)$ & $(1693)$ \\
\hline
\end{tabular}

Notes: MWTP is calculated using equation (12) for the sample-mean respondent, except DYS $=0$ or 1 as shown. Log WTP is transformed to dollars by exponentiation (hence the estimate is the median over the error term). Robust standard errors are in parentheses: ${ }^{*}$ significant at $10 \%$; ${ }^{* *}$ significant at $5 \%$; ${ }^{* * *}$ significant at $1 \%$. 
Table 8. Total WTP to improve skills to "very good"

\begin{tabular}{lcc}
\hline & Non-DYS & DYS \\
\hline Reading speed & 365 & 717 \\
& $(372)$ & $(510)$ \\
Reading aloud & 106 & 549 \\
& $(135)$ & $(427)$ \\
Memory & 436 & 558 \\
& $(416)$ & $(457)$ \\
Pronunciation & 226 & 574 \\
Information retrieval & $(229)$ & $(470)$ \\
& 862 & 970 \\
All skills & $(632)$ & $(653)$ \\
& 1529 & 3023 \\
\hline
\end{tabular}

Notes: Estimated WTP to improve self-reported skill level from current level to "very good." Calculated as the product of self-reported skill improvement (Table 2) and marginal WTP for improvement (Table 7). Standard deviations calculated assuming estimates of skill improvement and of MWTP are independent. 
Table 9. Validity test: Single-bounded vs. double-bounded estimates

\begin{tabular}{lcc}
\hline & Single-bounded & Double-bounded \\
\hline Reading speed & $-1.079^{* * *}$ & $-1.328^{* * *}$ \\
Reading aloud & $(0.318)$ & $(0.292)$ \\
& $-1.116^{* * *}$ & $-1.440^{* * *}$ \\
Memory & $(0.379)$ & $(0.322)$ \\
& $-0.821^{* * *}$ & $-0.843^{* * *}$ \\
Pronunciation & $(0.289)$ & $(0.230)$ \\
& $-1.221^{* * *}$ & $-1.717^{* * *}$ \\
Information retrieval & $(0.429)$ & $(0.357)$ \\
& $-1.759^{* * *}$ & $-1.550^{* * *}$ \\
All skills & $(0.402)$ & $(0.306)$ \\
& $-2.010^{* * *}$ & $-1.684^{* * *}$ \\
\hline
\end{tabular}

Notes: All regressions use maximum likelihood estimation. Dependent variable is log WTP for indicated skill. Regressions follow from equation (10). Single-bounded estimates are from a probit equation, assuming the residual variance equals one. Double-bounded estimates correspond to the estimates reported in Table 6 divided by the estimated standard deviation of the error (sigma). Robust standard errors are in parentheses: * significant at $10 \%$; ${ }^{* *}$ significant at $5 \%$; ${ }^{* *}$ significant at $1 \%$. 



Figure 1. Willingness to pay to improve all skills jointly compared with improving single skill

The figure displays the distribution of $t$-values from 100 replications. We divide the population into random sub-samples 100 times. For each replicate, we run five regressions similar to those in Table 6 but including an additional variable coded 1 for respondents in one sub-sample (who value all interventions simultaneously) and 0 for respondents in the other sub-sample (who value a single skill). The regression model is: $C_{i t}(e, w, s)=\alpha_{1} A l l_{i}+x_{i} \beta+\xi+\epsilon_{i t}$, where $e$ represents the increase in skill $s, \mathrm{w}$ represents current wealth, $A_{l l}$ is equal to 1 if respondent $\mathrm{i}$ belongs to the sub-sample answering to the question concerning an increase in all skills and 0 otherwise, $x_{i}$ represents demographic variables, $\xi$ is a constant term, and $\epsilon_{i t}$ rationalizes idiosyncratic unobserved variation. Over all replications, coefficient $\alpha_{1}$ was positive and mean values (standard deviations) were $1.14(0.20)$, $1.78(0.24), 0.67(0.16), 1.74(0.24)$ and 0.61 (0.20) for reading speed, reading aloud, memory, pronunciation and information retrieval, respectively. 


\section{Appendix}

To derive equation (5) we take equation (3),

$$
\frac{\partial C}{\partial s}=\frac{\frac{\partial U}{\partial S}}{\frac{\partial U}{\partial w}}-\frac{\frac{\partial u}{\partial s}}{\frac{\partial U}{\partial w}}
$$

and we replace the first term on the RHS using equation (2) which yields:

$$
\frac{\partial C}{\partial s}=\frac{\partial C}{\partial e}-\frac{\frac{\partial u}{\partial s}}{\frac{\partial U}{\partial w}}
$$

Next we multiply and divide the second term on the RHS by the marginal utility in case of no skill improvement and obtain,

$$
\frac{\partial C}{\partial s}=\frac{\partial C}{\partial e}-\frac{\frac{\partial u}{\partial s}}{\frac{\partial u}{\partial w}} \frac{\frac{\partial u}{\partial w}}{\frac{\partial U}{\partial w}} \equiv \frac{\partial C}{\partial e}-\frac{\partial C(0, w, s)}{\partial e} \frac{\frac{\partial u}{\partial w}}{\frac{\partial U}{\partial w}}
$$

which implies:

$$
\frac{\partial C(0, w, s)}{\partial e}=\frac{\frac{\partial C}{\partial s}-\frac{\partial C}{\partial e}}{-\frac{\frac{\partial u}{\partial U}}{\frac{\partial U}{\partial w}}} .
$$

Solving equation (4) for the denominator on the RHS and substituting the result yields:

$$
\frac{\partial C(0, w, s)}{\partial e}=\frac{\frac{\partial C}{\partial e}-\frac{\partial C}{\partial s}}{1-\frac{\partial C}{\partial w}}
$$


Table A1. Willingness to pay regression results without time cost

\begin{tabular}{lcccccc}
\hline & $(1)$ & $(2)$ & $(3)$ & $(4)$ & $(5)$ & $(6)$ \\
& $\begin{array}{c}\text { Reading } \\
\text { Speed }\end{array}$ & $\begin{array}{c}\text { Reading } \\
\text { Aloud }\end{array}$ & $\begin{array}{c}\text { Memory } \\
\text { Pronun- } \\
\text { ciation }\end{array}$ & $\begin{array}{c}\text { Information } \\
\text { retrieval }\end{array}$ & All skills \\
\hline Dyslexic & 0.212 & $1.029^{*}$ & -0.00197 & 0.442 & -0.0298 & 0.258 \\
Baseline skill & $(0.346)$ & $(0.563)$ & $(0.229)$ & $(0.426)$ & $(0.237)$ & $(0.246)$ \\
& $-2.485^{* * *}$ & $-3.695^{* * *}$ & $-1.092^{* * *}$ & $-3.233^{* * *}$ & $-2.088^{* * *}$ & $-2.305^{* * *}$ \\
White & $(0.608)$ & $(1.025)$ & $(0.300)$ & $(0.804)$ & $(0.444)$ & $(0.513)$ \\
& -0.261 & -0.269 & -0.178 & -0.295 & -0.285 & -0.272 \\
Female & $(0.471)$ & $(0.693)$ & $(0.274)$ & $(0.513)$ & $(0.298)$ & $(0.267)$ \\
& $-1.201^{* * *}$ & $-1.158^{* *}$ & $-0.465^{* *}$ & -0.183 & -0.239 & $-0.398^{* *}$ \\
Income & $(0.329)$ & $(0.530)$ & $(0.187)$ & $(0.358)$ & $(0.197)$ & $(0.187)$ \\
Mothers' & 0.0535 & 0.0883 & 0.0211 & -0.0175 & $0.0547^{*}$ & $0.106^{* * *}$ \\
education & $(0.0506)$ & $(0.0725)$ & $(0.0322)$ & $(0.0599)$ & $(0.0324)$ & $(0.0313)$ \\
& & & & & & \\
Constant & 0.258 & 0.311 & 0.218 & 0.344 & 0.157 & 0.233 \\
& $(0.312)$ & $(0.547)$ & $(0.196)$ & $(0.362)$ & $(0.201)$ & $(0.195)$ \\
Sigma & $7.033^{* * *}$ & $6.096^{* * *}$ & $6.657^{* * *}$ & $6.677^{* * *}$ & $7.116^{* * *}$ & $7.731^{* * *}$ \\
& $(0.725)$ & $(1.142)$ & $(0.385)$ & $(0.856)$ & $(0.432)$ & $(0.507)$ \\
& & & & & & $1.36^{* * *}$ \\
& $1.86^{* * *}$ & $2.56^{* * *}$ & $1.29^{* * *}$ & $1.87^{* * *}$ & $1.34^{* * *}$ & $1.361)$ \\
\hline
\end{tabular}

Notes: All regressions are maximum likelihood estimates. Dependent variable is log WTP for indicated skill. Regressions follow from equation (10). Improvements are computed as explained in Table 2. Robust standard errors are in parentheses: ${ }^{*}$ significant at $10 \%$; ${ }^{* *}$ significant at $5 \%$; ${ }^{* * *}$ significant at $1 \%$. 
Table A2. Marginal willingness to pay for improvement intervention without time cost

\begin{tabular}{lccc}
\hline & Mean & Non-DYS & DYS \\
& DYS $=0.23$ & DYS $=0$ & DYS $=1$ \\
\hline Reading speed & $1061^{* * *}$ & $1016^{* * *}$ & $1290^{* * *}$ \\
& $(260)$ & $(250)$ & $(316)$ \\
Reading aloud & $453^{* * *}$ & $372^{* * *}$ & $1010^{* * *}$ \\
& $(126)$ & $(103)$ & $(279)$ \\
Memory & $929^{* * *}$ & $927^{* * *}$ & $943^{* * *}$ \\
& $(255)$ & $(258)$ & $(261)$ \\
Pronunciation & $781^{* * *}$ & $713^{* * *}$ & $1136^{* * *}$ \\
& $(195)$ & $(178)$ & $(282)$ \\
Information retrieval & $1771^{* * *}$ & $1790^{* * *}$ & $1772^{* * *}$ \\
& $(371)$ & $(382)$ & $(377)$ \\
All skills & $4308^{* * *}$ & $4077^{* * *}$ & $5406^{* * *}$ \\
& $(967)$ & $(900)$ & $(1213)$ \\
\hline
\end{tabular}

Notes: All regressions are maximum likelihood estimates. Dependent variable is $\log$ WTP for indicated skill. Regressions follow from equation (10). Improvements are computed as explained in Table 3. Log WTP is transformed to dollars by exponentiation (hence the estimate is the median over the error term). Median MWTP is calculated following equation (12). Non-DYS and DYS estimates are computed allowing the median MWTP to vary with dyslexia status. Robust standard errors are in parentheses: * significant at $10 \%{ }^{* *}$ significant at $5 \% ;{ }^{* * *}$ significant at $1 \%$. 